\title{
11. Disciplining Academic Women: Gender Restructuring and the Labour of Research in Entrepreneurial Universities
}

\author{
Jill Blackmore
}

This chapter examines the 'gendered nature of the social organisation of research and scientific knowledge production' and in particular the gendered nature of the corporatisation of higher education (Knorr-Cetina 1999, 9). It argues that the conditions of labour of the entrepreneurial university and underlying marketoriented instrumentalism has changed the nature of the relationship of higher education with the public, with the individual student and the academic, in ways that are gendered. 'Markets do not make social distinctions disappear, they regulate interaction between institutions e.g. families and education, and "instrumentalist" status distinctions, bending pre-existing cultural value to capitalist purposes' (Fraser and Honneth 1998, 58). The dominant neoliberal policy 'doxa', with its economistic view of higher education in relation to the knowledge economy, is an ideology which shapes a range of constantly changing discursive and material practices (Epstein et al. 2008). This is 'not so much a "new" form of liberal government, but rather a hybrid or intensified form of it' that works through and on subjectivities that are racialised, gendered, classed and sexualised (Bansel et al. 2008, 673).

Neoliberal reforms have produced new forms of governmentality premised upon comparison. Within the social field of higher education, the rules of the game have changed over the past two decades (Naidoo 2004). Internally, elite universities seek to maintain their comparative advantage relative to newer universities in the Australian market as external pressures intensify. These pressures include the entrance of new players (Singapore, China, Indonesia) and increased competitiveness of established players (USA, UK, Germany) in the international 
education market. All strive for 'world excellence' status. The sector has also had difficulty maintaining its boundaries as market principles have penetrated into the structures, processes and language of higher education (Lingard and Rawolle 2011), with the blurring of boundaries between higher education and other fields (politics, journalism, publication, business) as well as the pressure to gain new sources of funding that provide more immediate economic benefits (Bourdieu 1990, 1988, 1986). The doxa of higher education as a public good has been unsettled as universities are no longer the only source or producers of knowledge legitimating what counts as valued knowledge (Marginson 2011).

Within global higher education markets, research remains critical to the distinctiveness of both the field and the status of an individual university and its positioning relative to the state and other educational providers. Bourdieu (1986) refers to the research activities of academics as scientific (research) capital that includes symbolic capital in terms of esteem, international networks and material capital or findings. What gets researched, how it is researched and how that research is valued, the symbolic capital, is also indicative of gendered power/knowledge relations within the gender regime of the academy and gender order of the wider society (Connell 2006). The following analysis draws from a three-year Australian Research Council (ARC) project on Leadership in the Entrepreneurial University: Diversity and Disengagement. The study involves intensive case study research through interview, documentary and policy analysis in three universities - a Group of Eight (Go8), a university of technology and a regional university - to identify differences between how institutional cultures, scale and disciplinary scope impact on who gets to lead and the nature of that leadership. It follows 15 years on from an Australian Research Council (ARC) study investigating educational restructuring in universities, schools and TAFE in post-Dawkins Australia in the mid-1990s. The chapter's title appeals to Foucault's notion of the dispersed disciplinary power relayed through discourse and power/knowledge relations. Policy texts and institutional practices have discursive and material effects in terms of how they discipline the humanities and social sciences more harshly as well as in the production of particular academic subjectivities (Bansel et al. 2008, Clegg 2008).

This chapter argues that we are experiencing a second phase of higher education restructuring that is also reconfiguring the social relations of gender within the field (Brooks and Mackinnon 2000, Currie et al. 2000, Deem 2003). The first phase of restructuring that unified, marketised and managerialised higher education systems (Blackmore and Sachs 2007) in Australia and the UK was nation-centric. The second phase emerges from the context in which academic capitalism has gone truly global, fuelled by new technologies and increasingly mobile students, academics and content (Slaughter and Leslie 1997). Higher education research is now closely tied to the national economy through priority setting by government 
research funders - the ARC and the National Health Medical Research Council (NHMRC). Quality, now the measure of distinction in education markets, is signified in research through research assessment (e.g. Excellence in Research for Australia (ERA); and the Research Excellence Framework (REF) in the UK) (Besley 2010). Quality in teaching and learning is being driven through a standardsbased agenda of the newly established Tertiary Education Quality and Standards Agency (TEQSA). Market distinctiveness is also produced through individual university compacts leading to greater institutional differentiation. This globalised phase of restructuring is characterised by the intensification of the processes of corporatisation (managerialism, marketisation and privatisation) that were emergent during the 1990s (Brooks and Mackinnon 2000; Blackmore and Sachs 2007; Marginson and Considine 2000). This resulted in a blurring of public/private provision, a renewed focus on branding and ranking, moves towards institutional restructuring to encourage interdisciplinarity, demand-driven online curriculum, industry partnerships and the intensification of academic work (Shapper and Mayson 2005; Epstein et al. 2008; Menzies and Newson 2008).

Serial restructuring and rebranding over two decades have had gendered effects because of the assumptions underpinning the processes, structures and practices work within the frame of gendered organisations. Universities are characterised in particular by a unique historical allocation of values associated with knowledge legitimation, production and dissemination that are reconfigured over time. Gender is evident in how research is understood and enacted in the:

- policy discourses and images of research that equate science and technology with innovation as the driver of economic growth to the neglect of the social and cultural;

- policies premised upon a normative science that fails to recognise the nature of quality research in different disciplinary fields where women are concentrated (Gillies 2008);

- redistribution of time and space in terms of how and where academics work, leading to work/life conflict more than balance and the impact on those with caring responsibilities (Pillay et al. 2013);

- individuals' capacity for mobility is becoming increasingly important in academic careers with women more bound to place (Menzies and Newson 2008; Jons 2011);

- gender division of labour in research management and practice with regard to who does what and who gets recognised in terms of esteem and leadership (Bell 2009; Coates et al. 2009);

- institutional cultural ethos and heightened expectations about research;

- competing policy discourses about teams and collaboration and competitive individualism of 'star' systems (Blackmore 2009a); and 
- reward systems where potential beats substantive record in promotions (Chesterman et al. 2003; Dever et al. 2008).

Markets also are socially constituted, despite the discourse of rational choice theories, produced through policy and often without any pre-existing demand. Markets allocate value and distribute resources and rewards. In particular, markets produce 'social settings that foster specific types of personal development and penalise others' (Bakker 1994, 4). In the case of the performative university, they encourage self-interest and self-promotion, being seen to be performing, thus producing an entrepreneurial intellectual habitus and managerial leadership habitus (Metcalfe and Slaughter 2008; Blackmore and Sachs 2007). Markets produce and exploit emotions of anxiety and desire. On the one hand, there is anxiety arising from the volatility of higher education markets of students, academics and providers. On the other, there is the passion of academics as researchers to achieve, to make a difference and to contribute, as many academics are ethically disposed to 'do good' (Macfarlane 2011). Markets are also gendered. Bakker $(1994,3)$ sees 'markets as institutions imbued with structural power relations and those have an asymmetrical gender dimension to them'. Gender is central to how the 'managed education market' works differentially in terms of what is valued, images of academic or entrepreneurial leadership, the division of labour, and who has the opportunity to become the internationally mobile strategic academic.

\section{Research, quality and the global market}

Australian universities during the $20^{\text {th }}$ century were nation-building enterprises with a strong public commitment, funded largely by government, a reactively autonomous social field in which research was considered to be part of everyday academic practice. Jane Kelsey $(1995,58)$ saw universities in the 1990s as primary sites of critique of the ideologies of neoliberal market theory, and therefore they were an 'obvious target for radical market oriented restructuring'. Post-1989, the Dawkins reforms set in train the processes of corporatisation of the academy - managerialisation, marketisation and privatisation - that restructured the higher education sector nationally. Universities are now transnational corporations with global reach and they are again being restructured within increasingly diverse and complex global higher education markets. The context is of heightened competition from older Anglo competitors and recent Asian players. Higher education markets also arise due to the lack of government funds and are thus increasingly driven by external demands of industry, government, NGOs and students. This means fewer research-driven agendas internal to the disciplines. External and internal education markets increasingly determine the value of knowledge, create reputations, distribute rewards, promote images of success, and form more entrepreneurial academic identities (Clegg 2008). 
Bourdieuan scholars now argue that decisions about the field of higher education are being made by those outside of the field more than those inside due to the globalisation of higher education policy, research, increased cross-national institutional arrangements, and international labour markets of students and academics (e.g. Naidoo 2004; Lingard and Rawolle 2011). This is evident with reduced numbers of academic and student and increased numbers of business representatives on university councils (Rowlands 2013). Internally, the field is increasingly porous not only due to greater seamlessness between the sectors of TAFE, universities and schools but also a blurring between public and private providers with the trend to privatisation (Marginson 2011). Other policy trends and institutional responses are emerging that impact on the social organisation of research and the positioning of women as academics and as future leaders in research, such as:

- shifting from quantity and capacity building to 'quality' and 'excellence' as defined by proxy citation indicators (ERA);

- shifting from merit and pure research to applied research with measurable use-value (industry partnerships);

- focusing on research concentrations, institutional environment and capacity building (ERA and ARC);

- encouraging differentiation between universities (global ranking and compacts); and

- producing the intensification (scope, scale and depth), diversification of academic labour (research only/teaching and research/teaching only), and the blurring between academic/professional roles.

\section{Gendering academic labour}

The internal higher education labour market comprises a well-defined historical gendered (and in many instances racialised) horizontal division of labour in which women academics are concentrated in more junior and casual or contract positions (Coates et al. 2010; Junor 2004; ABS 2012), undertaking more teaching than their male counterparts (Bell and Bentley 2005). Bell $(2010,48)$ reports that 'significant international studies are providing evidence of persistent patterns of horizontal segregation (by discipline) and vertical segregation (by level of seniority and measures of esteem) of women in higher education'. ${ }^{1}$

\footnotetext{
1 In Australia, in the period 2003-11 women have increased from 19.1 to 27.3 per cent representation in above senior lecturer levels, from 33.7 to 42.2 per cent senior lecturer, 46.4 to 51.5 per cent lecturer and 53.2 to 54.9 per cent below lecturer full-time or fractional full-time positions, not including casual staff. Women increased from 62.2 per cent to 65.6 per cent full-time and part-time non-academic staff; an increase from 52.2 to 55.9 per cent of all staff (ABS 2012).
} 
Women's numerical increase obfuscates the changing nature of the research enterprise (Chesterman 2008). Pipeline theory assumes that a critical mass of women, particularly with the feminisation of the academy, will be promoted into managerial and research leadership. Yet many women do not progress past senior lecturer, or associate professor or head of school (Bell 2010). Even when women achieved numerical parity in the Australian Research Council grants in 2013, they were not usually principal investigator and they peaked in ARC successes a decade later than men, at 65-70 years (ARC 2012). The Federation of Australian Scientific and Technological Societies concluded that gender segregation contributes to the attrition of women from the scientific professions (Bell 2009), as in the UK (Guderley 2013), particularly since women are paid on average less than men internationally (ranging from 75 per cent to 90 per cent) (Welch 2012). Even highly successful female research leaders continue to feel excluded from the networks that build research capacity. An MIT study of women in science and engineering concluded that marginalisation increases as they progress, because they endure 'differences in salary, space, awards, resources, and response to outside offers ... despite professional accomplishments equal to those of their male colleagues' (cited by Bell 2009, 442).

Importantly, this horizontal and vertical gendered division of labour repeats itself inter-generationally. Any increase in Australian women's participation has been in traditional subjects, with three per cent increases in science, engineering and technology from a low base. Yet female participation in the professional fields generally has increased over 11 per cent (Bell 2009):

As is the case across most of the developed world, women have long held top spot in the 'typically female' professions of education and health (where women are three out of four Australian students and a quarter of professors), food and hospitality, the arts and humanities, and creative arts (where two thirds are female) (University World News 2009).

The UNESCO Digest (2009) found that men outnumber women 'in engineering, manufacturing and construction in all countries for which data were available', with the opposite proving true 'for the cohort of graduates in education, humanities and arts, social sciences, business and law, and health and welfare, where, in almost nine out of ten countries women outnumber men'. Even then, a concentration of women does not necessarily translate into research leadership. Collins et al. (2011) found multiple factors explained the difference to female academics' advancement as leaders in New Zealand universities: university environment; invisible rules; work relationships; proactivity; and personal circumstances. To this I would add increased institutional differentiation and the changing nature and intensification of academic labour. 


\section{Institutional differentiation and branding}

Heightened global competition in higher education has changed the rules of the game, making research the indicator of quality in university rankings (Marginson 2010). National research discourses focus on quality (world excellence) and innovation (applied research and entrepreneurialism) on the one hand and efficiency and alignment with national priorities on the other. Both governments and funders demand more immediate returns for investment. The 1990s emphasis on research capacity building and quantity saw an increase in female participation as students and academics. But research assessment (ERA), with its focus on quality, institutional differentiation and research performance, together with compacts, has encouraged university executives to specialise and strategically position each university in niche markets. The argument in the Australian context is that universities can no longer afford to offer everything to everyone, thus putting the notion of a liberal comprehensive university under threat. Re-branding and the identification of strategic research foci produces more differentiated systems of education, such as in the US and Canada, between research-intensive, comprehensive teaching and research and undergraduate or teaching institutions. In terms of equity, these usually produce gender-gap salary differentials, with women in the majority in the colleges, non-research, more generalist or third-stream institutions (Gordon and Whitchurch 2010). Already the ERA repositions smaller and newer universities without strong research environments as struggling to survive (e.g. the amalgamation between the regional University of Ballarat and the Gippsland campus of Monash in 2013). Greater differentiation within the system will impact on the quality of teaching when dissociated from a research base and creates an underclass of students, largely in regional and newer universities, which recruit most of the students from lower socio-economic and more educationally diverse backgrounds.

\section{Leading research: Normative science and the unbundling of academic labour}

Policy creates markets, and allocates values as well as resources. Policy is symbolic of what counts, discursively conflating science and technology with innovation in public discourses. The 'quality' and efficiency government agendas have also led to reductionist measures based on metrics in research assessment (Besley 2010). ERA is just one driver that enhances the advantage of those in the maledominated material or 'hard' sciences relative to the social sciences. Particular forms of 'scientific capital' (Bourdieu 1988) are valued more. These agendas have changed the disciplinary practices of research in the social sciences and 
humanities, with large concentrations of female scholars and students where quality and esteem factors, the game changers in the field, are often individuallywritten books and even edited collections, not journal articles.

Institutional policies also skew towards the hard sciences as more 'productive' while contributing lack of student demand to the downsizing of the humanities and social sciences (e.g. Latrobe University, University of Melbourne). In anticipation of some form of research assessment since 2003, universities foregrounded research in strategic plans; created distinctiveness through research centres and built capacity; reconfigured disciplines to create research concentrations; formed collaborative research networks; intensified and sped up research training; recruited star graduate students and researchers; and heightened competition for research funds (Blackmore 2009b). 'Big science' is where women are not research leaders (e.g. Collaborative Research Centres). Cross-institutional and international collaborations rely on big money through industry networks and academic mobility, which women tend not to have to the same degree (Jons 2011; Metcalfe and Slaughter 2008).

Research assessment has had flow-on effects. First, the audit culture means universities now require individual academics to align their research with faculty, university and national priorities through performance appraisal. In practice, performance management becomes a form of internal and internalising control of academics by managers in the production of the high-performing (and conforming) academic (Bansel and Davies 2010). Implicitly, the threat in enterprise bargaining is that research and teaching positions can be made 'redundant' to university priorities. Managers now scrutinise those organisational units defined by ERA as 'low-quality', even though they do not coincide with fields of research (FoR) codes. Often poor performance of a FoR was more a consequence of misjudged institutional tactics and poorly constituted fields of research categories than poor quality research. The audit culture also means that academics need to be managed better through centralised strategic plans so they do not research 'whatever they want'. The well-managed researcher now strategises in performance plans what research they do, who they do it with, how they do it, where they publish it, and ostensibly whether it aligns with institutional and national goals. Much of this performative work requires some fabrication to achieve the necessary alignment (Ball 2000; Blackmore and Sachs 2007).

Secondly, all universities are emulating the research-intensive universities, resulting in an increased diversification and unbundling of academic labour. Because ERA 'counts' the 'output' of all research active academic staff within a field of research named by the university, universities are increasingly differentiating between academics based on level of research 'activity' and usevalue (active researcher/teacher). An academic's notional core work of teaching, 
research and service has been unbundled into research-only, teaching and research, and teaching-only positions (Macfarlane 2011). This trend favours research-intensive universities with well-established science and technology concentrations and industry, government and philanthropic partnerships (Metcalfe and Slaughter 2008).

Thirdly, research assessment has paradoxically reinvigorated disciplinarity through abstract fields of research codes at a time when knowledge economy discourses and university restructuring focus on interdisciplinarity, applied research partnerships and collaboration in large teams. At the same time, institutional restructuring has led the social sciences, humanities and arts to be amalgamated into larger faculties redesigned into new 'disciplinary formations' (e.g. creative industries) while seeking efficiency. Individual sociologists, historians and anthropologists are increasingly embedded within interdisciplinary centres, focusing on applied problems with social, medical, material sciences and technology. One consequence is that disciplinary training in the numerically feminised fields of social sciences and humanities is increasingly reliant on elite institutions. Another is that the social sciences and humanities as heterogeneous disciplines are assumed to have one voice among multiple voices of the material, biological and cognitive sciences at the executive table. The shrinking of the fields of social science and humanities, as languages previously, not only skews university priorities and profiles towards the 'hard' sciences but endangers long-term sustainability in terms of building disciplinarity capacity in what have traditionally been feminised fields. At the same time, ERA highlights ambiguity in the notion of what constitutes a discipline or field of study and the contradictory policies around interdisciplinarity. For example, education characterised as a field of research never 'scores' well in research assessments internationally or in Australia (Furlong and Lawn 2011). Education is characterised by its multidisciplinarity, its inclusion of scholarship on teaching practice, its professional orientation and its high level of feminisation (Seddon 2013). Women's studies, highly interdisciplinary, are under threat. Torr $(2006,60)$ argues that in the UK:

full-time positions in women's studies departments are limited and subject areas outside of women's studies are still largely organized along traditional disciplinary lines ... the setting of stricter guidelines for postgraduate training at a national level ... limits the extent to which graduate level programmes can be interdisciplinary in nature. 


\section{Implications for women as research leaders}

Research assessment in Australia as elsewhere has led to a focus on research leadership and recruitment, quality and excellence. Workloads are increasingly based on incremental point systems that require sustained if not escalating performance in terms not only of publication and grant churn but also leadership and service. Universities have ratcheted up expectations of all academics to publish in particular journals and to measure their achievements by citations while also informing policy and practice. Promotion committees utilise measurable indicators (ranking of journals, student evaluations, citations) as proxies for quality. A new academic habitus is being produced as academics internalise these expectations and processes of assessment (Bansel et al. 2008). This ratcheting up of expectations of 'quality' research and teaching and service has led to academic overload with a number of gendered effects. While both men and women enter postdoctoral research-only appointments, the early trend suggests that teaching-only appointments will become the default positions for tenured early-career women academics, impacting significantly on their academic status and career prospects as traditional teaching and research appointments decline (quoted in Lane 2012). International studies indicate that women are exiting the sciences as a consequence of these rising expectations and conditions (Bell 2009; Guderley 2013).

Furthermore, the increased scope, scale and depth of what constitutes research leadership means track record 'relative to opportunity' that recognises women's broken career trajectories is often ignored in committees where sustained track record dominates. Having children is not the norm. Yet:

life choices (to delay entering the academy, to undertake periods of part-time or casual work, to commence a career as a research assistant, to have children, to care for aging parents) do not alter one's capacity to produce high quality research outcomes, nor indeed to produce 'breakthrough research', but they may impact on the quantum of research productivity, the strength of research networks and mentors, professional mobility and therefore profile (Bell and Bentley 2005, 1).

A sustained research record is not only unsustainable for most, but also limits how we understand excellence and quality. 'Although research is only one strand of academic work (in tandem with teaching and community service) research has, in the modern university, been accorded higher status as the defining feature of the academic enterprise' (Bell and Bentley 2005, 358). Furthermore, research policies are premised upon a normative model of big science - large teams, scaled-up projects, industry partnerships, individual and institutional collaboration and research concentrations. Yet reward systems are premised upon academic hierarchies with a few individual winners. 
The logic of sustained research record encourages the unbundling of research from teaching and is most evident in the research-intensive universities where women in research are in decline.

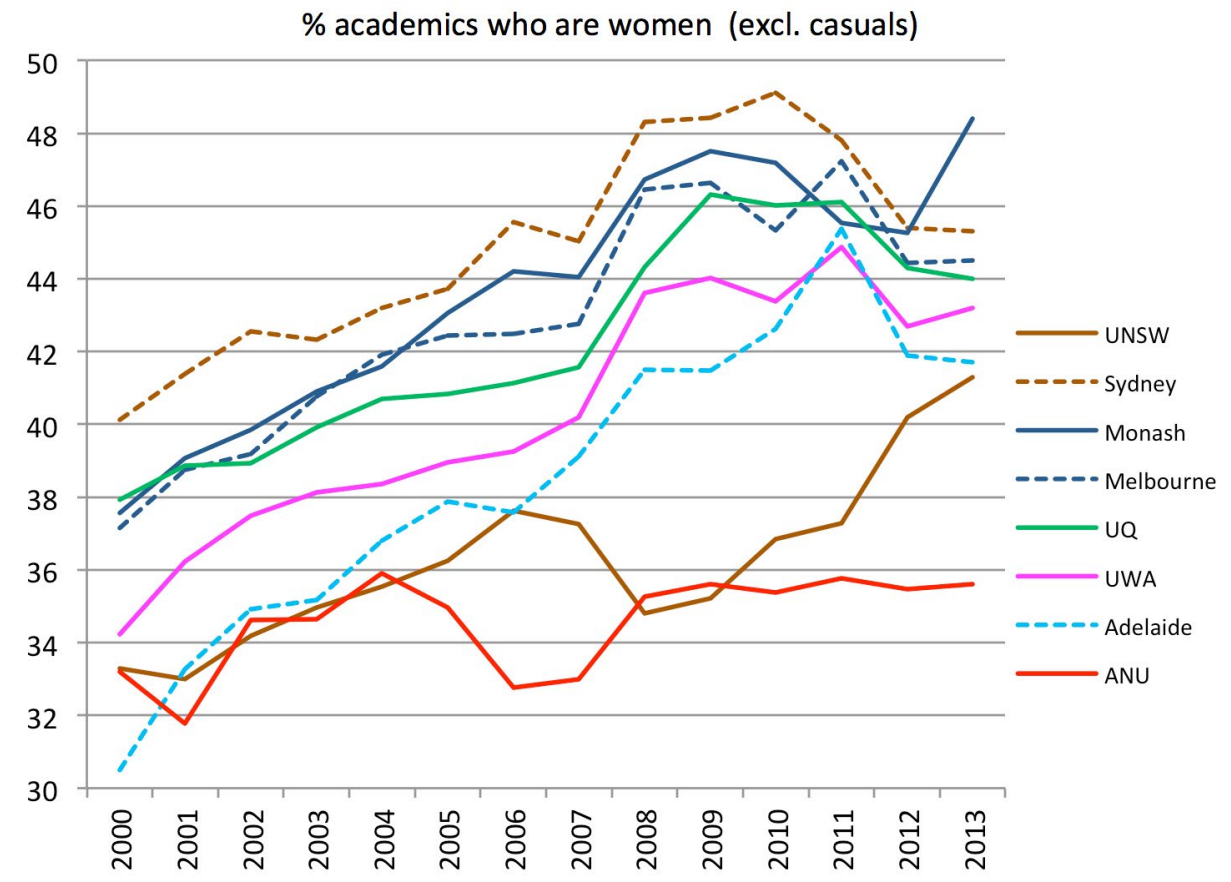

Figure 11.1: Gender bender: Women in academic decline

Source: Susan Feteris, with permission. Retrieved 17 February 2014, with data from http://education. gov.au/staff-data.

Feteris (2013, also cited in Lane 2012) argues that the decade of expansion of funding and capacity post-2000 saw female academic numbers in the Go8 universities increase to 50 per cent, followed by a post-ERA decline in researchonly roles and an increase of women in teaching-only roles of 10 per cent. 'Many Go8 staff who took voluntary departure or forced redundancy packages were women' (Feteris cited in Lane 2012). Women lose out as they tend to do more teaching and pastoral care and thus are readily made redundant. Students also lose out as key researchers focus on research-only and not research and teaching, as opposed to the US where star professors are also expected to teach (as evident in MOOCs).

Finally, research leadership is contingent on mobility, flexibility, industry and government connections to source funding. Metcalfe and Slaughter (2008) argue that private funds tend to be in the areas of technology, and material and biological sciences, while women tend to be concentrated in the health sciences, law, social sciences, arts and humanities - fields more reliant on 
community, government and social philanthropy. As higher education becomes more globalised, mobility is necessary to attend conferences, teach and develop research collaborations: 'Higher education is increasingly a globalised occupation in which workers are expected to participate in global activities and to have skills, expertise and attributes that are of world standing' to gain promotion to the professoriate (Boden and Epstein 2006, 252; Boltanski and Chiapello 2005). While internationalisation and cross-national research collaborations offer new possibilities, this is often at a financial and personal cost to academics, particularly early-career academics with young families as they tend not to have discretionary research funds to draw upon. At the same time, university employers push in enterprise bargaining for flexibility by extending the hours that academic (and professional staff) work with online technologies, allowing teaching to occur any place any time. Technologies are a two-edged sword: facilitating working from home and therefore more family-friendly, but also invading private time and space. Again, research indicates that women tend to do more domestic work when working at home than male academics due to the lack of change in the domestic gender division of labour: the workplace is respite (Coates et al. 2010).

\section{Managing research and the gender division of labour}

The focus on research has produced a proliferation of managers of research (academic and non-academic) as it now requires 'managed alignment' of the individual to the collective research enterprise, institutional plans and specialisms, and national priorities stated in university compacts. The intensified focus on managing research has produced a proliferation of pro vice-chancellors (PVCs) and deputy vice-chancellors (DVCs). While there is recognition that research managers at DVC and PVC level need to have credibility in terms of a research profile, that credibility is associated with science. Scott et al. (2011) in a large-scale study found that of the 21 who identified as being in PVC and DVC positions, 19 were male with disciplinary backgrounds in the Natural and Physical Sciences (13/31) followed by Society and Culture (6/31), Education (4/31) and Health (4/31). Most DVCs of Research have backgrounds in the material and biological sciences and most are male. This reproduces the gender division of labour between Humanities and Social Sciences (HASS) and Science, Technology, Engineering and Maths within research management and hegemonic mindsets that impacts on the rules of the research game institutionally in terms of the distribution of funds (e.g. scholarships, post-doctoral fellows, grants and awards). It confirms the invisible micro-politics of gender that associates particular forms of knowledge, authority and leadership within the academy (Morley 2013a). 


\section{Reconfiguration of the academic workforce: Diversification, de-professionalisation and casualisation}

The focus on research is occurring at the same time that academic work is being reconfigured, marked by its casualisation and feminisation (ABS 2012). Teaching is being unbundled into instructional design, tutoring, assessment and technical support, all undertaken by 'experts' with blended learning (multimodal online/ face-to-face) (McWilliam and Taylor 1998). While this provides scope for the professionalisation of administrative work (itself feminised) and the emergent field of e-learning and ICT (Gordon and Whitchurch 2010), arguably it signals a de-professionalisation of academic work (Shapper and Mayson 2008). Research is also being unbundled due to the blurring/merging of academic and administrative roles. Women with doctorates are moving into research administration rather than staying as academics, as it is understood to be a more 'controllable' environment (Whitchurch 2013). Meanwhile, academics have become amateur managers of research supported by an ever-expanding cadre of specialist full-time research management professionals (Whitchurch 2013). 'Contradictory tensions surrounding the historical and cultural meaning of female identity and female work are played out' (Dillabough and Acker 2005, 129) as new fields of feminised administrative work in research are developing at the same time that teaching is being feminised and de-professionalised and research is re-masculinised.

Overall, the conditions of academic work are radically altering with the rise of contractualism. Institutional flexibility is reliant on the casualisation and intensification of academic labour (Reay 2000). ${ }^{2}$ The rapid increase of researchonly contract positions is reliant on soft money, encouraging grant churn to attract funds to maintain their employment. Contracts are also being proposed for the professoriate as they are increasingly incorporated into line management in performance appraisal and pseudo-employment relationships. Researchers now recruit, manage and undertake performance reviews of staff as management/ administration has been dispersed down. New learning and management technologies and the accumulation of big data for digital archives are upscaling the management work of research. This intensification drains academic time and energy, produces anxiety, and diverts and detracts from research. Bexley et al. (2011) found that two-thirds of Australian academics in their sample feel the job is now overwhelming.

2 In Australia, the staff:student ratio has trebled since 1996, a trend exacerbated with the caps removed from enrolments, with casual staff accounting for more than half of staff increases while continuing staff decreased from 63.6 per cent to 59.3 per cent (Junor 2004; Coates et al. 2010). 


\section{The next generation?}

Academic life is marked by ambivalence, contradiction and paradox (Hearn 2000; Blackmore and Sachs 2007). The self-managing academic both opposes and accommodates the corporatisation of their everyday practice as they struggle between the dulling effects of compliance regimes and their desire to excel, being both competitive and collegial (Bansel and Davies 2010). At the same time, they are sidelined as decision-makers, experts and creative agents within their own institutions (Boden and Epstein 2006). Due to the normative pressures of science, particular fields of research are becoming redefined, offloaded or more difficult to do, in terms of who does research with whom and what research gets done.

This has implications for the future generation of researchers. First, in terms of the pipeline from graduate into the academy. While there are significantly higher numbers of women in undergraduate programs, this decreases in areas of science, technology and engineering as they progress to postgraduate. From 2002-10 a higher proportion of Australian graduate students are in information technology (29 per cent), agriculture, environment and related studies (28 per cent) and management and commerce (25 per cent), with the greatest expansion in engineering compared to smaller expansion in health and education and a small reduction in social science and larger fall in management (ABS 2012). Thus research resources and university infrastructure have moved significantly towards the 'hard sciences' and technology, where there are fewer women.

Secondly, the image of the star female academic moving up to become a professor by building a sustained research record is becoming more distant for many young women (Diezmann and Grieshaber 2009). A Berkeley study of one thousand graduate students (Mason 2008) demonstrated a significant gender gap of 10 per cent between male students who saw an academic career, and female students who saw choices between having children and being a research professor, of more likely moving to follow a partner and being less able to maintain sustained research, and therefore more likely to be in teaching. Furthermore, female graduates are much more likely than their male counterparts to complete their $\mathrm{PhD}$ as a solo project and less likely to be part of a research group and to pursue their $\mathrm{PhD}$ for intrinsic motivations such as intellectual and academic development, personal satisfaction, or interest rather than career (Dever et al. 2008). Being involved in a research group for four years develops the collaborative and networking skills most likely to impact on future employment opportunities and career paths (Dever et al. 2008, 1). Among graduate students, a higher proportion of women were in insecure and part-time jobs, with the gender difference most pronounced in research-intensive universities and for 
those with children. Fewer females were in supervisory or managerial positions and 90 per cent of male graduates and 69 per cent of females with children were working full-time (Dever et al. 2008). Bexley et al. (2011) found that most early-career researchers, while committed to their discipline, to research, and to teaching, have long-term plans of exiting the sector or moving overseas due to levels of stress, lack of tenure and work overload.

\section{Conclusion}

The above trends have implications for both gender equity and universities. Universities are less family friendly for everyone, but more so for women. Current workloads and expectations exacerbate existing incompatibilities between work and life (Pillay et al. 2013). The skewing of Australian universities towards the sciences and technology also means there is a shrinking pool of available courses and supervisors to build research capacity in HASS and limits the ways in which HASS provides different ways of understanding the world. Equally, Scheibinger and Schraudner (2011) argue that science, medicine and engineering cannot claim excellence without greater involvement of women researchers.

But this is about more than increasing the percentage of women into science and technology or leadership. It is about the nature and role of the 21 st-century university and the challenge to notions of the liberal comprehensive university. As MacIntrye $(2010,36)$ argues, the Bradley Review mentions briefly the importance of universities 'as a cornerstone of our legal, social, economic and cultural institutions' then fails to elaborate on what that means. Policies around the knowledge economy refer to responsiveness, relevance, rankings, international best practice and instant, obvious and measurable use-value but not the public good. Macintyre (2010) argues that the distinctiveness of the university in a democratic society is that it encourages independent critical thinking and is not totally framed by advanced capitalism. This distinctiveness requires both academic freedom and critical inquiry - both central to innovation - and a degree of institutional autonomy (Blackmore 2003; Marginson and Considine 2000). Macfarlane (2010) argues for the need to revive the notion of intellectual leadership within the academy, to reassert the role of the academic to be a critic and advocate. Academic leadership informs critical professional practice, critiques policy, and provides an intellectual forum that widens the notion of public interest and public good. Neoliberal policy reduces universities to the production of instrumental knowledge premised upon economic values that ignores the social and political role of universities, renders them as just another transnational corporation out to make a profit. Marginson $(2011,411)$ comments: 'If the work of higher education institutions is defined simply as 
the aggregation of private interests, this evaporates the rationale for higher education institutions as distinctive social foundations with multiple public and private roles. The private benefits could be produced elsewhere.'

Martha Nussbaum (2010) argues that the focus on profit offers an impoverished view of education and of what constitutes powerful research, which can produce a good society for everyone. Ackers $(2000,2)$ identifies a 'tie between gender and an organisation's most fundamental values and practices ... that contributes to such problems as inefficient decisions, unclear expectations and excessive controls'. The deep instrumentalism and functionality of neoliberal policies lacks any understanding of collegiality, collaboration and the premises of academic professionalism based on mutuality and trust or how diverse ontologies, epistemologies and politics are more likely to lead to greater 'productivity', and are more conducive to research and a better society. Ohrn et al. $(2009,4)$ reflect in the European context on the contradictions within contemporary gender relations in academia that 'on the one hand traditional masculinities are losing ground as growing numbers of women position themselves in research, and on the other hand ... pressures from a performative culture strengthen structures working to the disadvantage of women and other groups not traditionally in power'. 
This text is taken from Through a Glass Darkly: The Social Sciences Look at the Neoliberal University, edited by Margaret Thornton, first published 2014, this version 2015 by ANU Press, The Australian National University, Canberra, Australia. 